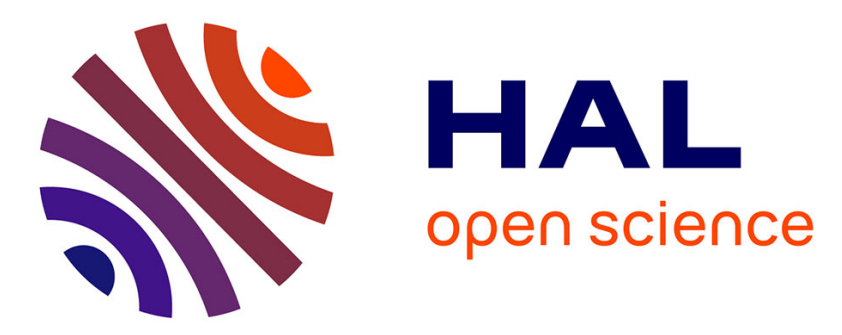

\title{
On the strategic use of representative democracy in international agreements
}

Grégoire Rota-Graziosi

\section{To cite this version:}

Grégoire Rota-Graziosi. On the strategic use of representative democracy in international agreements. 2011. halshs-00562632

\section{HAL Id: halshs-00562632 \\ https://shs.hal.science/halshs-00562632}

Preprint submitted on 3 Feb 2011

HAL is a multi-disciplinary open access archive for the deposit and dissemination of scientific research documents, whether they are published or not. The documents may come from teaching and research institutions in France or abroad, or from public or private research centers.
L'archive ouverte pluridisciplinaire HAL, est destinée au dépôt et à la diffusion de documents scientifiques de niveau recherche, publiés ou non, émanant des établissements d'enseignement et de recherche français ou étrangers, des laboratoires publics ou privés. 


\title{
On the strategic use of representative democracy in
}

\section{international agreements*}

\begin{abstract}
We consider as endogenous the choice of the delegation' rule in a political integration process between two countries. We study three potential types of delegation: strong, weak or no delegation, this last case corresponding to a referendum. We show that populations decide to bind themselves by delegating the national policy decision to a "powerfull conservative representative", in order to improve their bargaining position. These non-cooperative behaviors of countries when they decide on their delegation rule induce negative political externalities between countries, which cancel the gains achieved by the internalization of economic externalities in the case of political integration. We then propose two extensions. First, we assume a pre-play game where the countries choose whether or not to initiate political integration. Secondly, we examine the consequences of ratification by referendum. We conclude that a Pareto improvement of the political integration process would be to specify within the international treaty itself the means for its ratification; more precisely, to incorporate a formal ratification procedure, corresponding to an ex post referendum.
\end{abstract}

Keywords: Delegation; International Agreements; Nash Bargaining Solution; Political Integration; Ratification; Referendum.

JEL classification: D72; H77.

Grégoire Rota Graziosi

CERDI-CNRS, Université d'Auvergne

65 boulevard François Mitterrand

63000 Clermont Ferrand, France

Email: gregoire.rota_graziosi@u-clermont1.fr

*I would like to thank Olivier Cadot, Bertrand Crettez, Guillaume Cheikbossian, Hubert Kempf, Wilfried Zantman, as well as seminar participants at Paris-1-Panthéon-Sorbonne (January 2006), at the European Public Choice Society Conference (April 2006, Turku, Finland) and at the European Economic Association Conference (August 2006, Vienna, Austria). The ACI "Local Public Goods, Politics and Economics" provided valuable financial support. 


\section{Introduction}

European political integration has come to a halt with the French and Dutch referenda on the European Constitution. Apart from the nature of the Constitution itself, this failure has raised some questions about the ratification procedures for international treaties. If political integration involves, by definition, an agreement between sovereign states, the implementation of this agreement and in particular the ratification process, remains the responsability of the states themselves. There are as many processes of ratification as there are countries. And, even though the ratification of the European Constitution involves more recourse to citizen opinion by open referendum than ever before, ${ }^{1}$ there is still a great diversity of ratification procedures.

Beyond the European construction, the deepening interdependence of national economies calls for more and more international agreements in order to enforce cooperations among countries. In this paper, we study some consequences of the constitutional design on the political integration' issue. By constitutional design, we mean the delegation rule and the possible ratification procedures. We try then to explain why centralization of decision making might fail, even if centralization involves cooperative behaviors. We propose a framework where the non-cooperative behaviors of countries when they decide on their delegation rule induce negative political externalities between countries, which cancel the gains achieved by the internalization of economic externalities in the case of political integration. We deduce that a potential Pareto improvement of international treaties is to impose a domestic referendum as the single valid ratification procedure. Indeed, this constraint reduces the negative effects of strategic delegation.

This paper is at the intersection of several strands of the literature on public and political economy. One concerns the political integration of sovereign countries. This issue has been widely debated in the literature on international policy coordination since the works of Hamada in the seventies on the fixed exchange rate regime. Monetary or fiscal policies became early subjects of this analysis (see Persson and Tabellini (1995) for a sur-

\footnotetext{
1 Eleven countries choose to ratify the European Constitution by referendum: Belgium, Denmark, France, Ireland, Luxembourg, Malta, Netherlands, Poland, Portugal, Spain, UK.
} 
vey of this literature). More recently, environment, health, education, or even knowledge are presented by economists, like Kaul, Grunberg, and Stern (1999), as transnational or global public goods, which also require some international coordination. In the literature on fiscal federalism, Oates' decentralization theorem presented a trade-off between the benefits of centralization of policy making and the costs of policy uniformity. However, Oates (1972) assumed a social planer who determines policies. Recent works in the "new" political economy, for instance Alesina and Spolaore (1997) or Bolton and Roland (1997), emphasize the political process of these policy choices and the incentives to centralize. This literature compares the costs of heterogeneity in large populations and the benefits to large countries or unions of countries in providing public goods or in increasing private incomes (see Alesina and Spolaore (2003) and Ruta (2005) for a survey). However, these studies and some of their developments, such as those of Gradstein (2004), or Goyal and Staal (2004), ${ }^{2}$ consider only direct democracy.

Another weakness of Oates' theorem is the assumption of policy uniformity under centralization. Lockwood (2002) and Besley and Coate (2003) renewed this standard approach by ending this assumption. Besley and Coate (2003) establish that for low spillovers, decentralization is preferable, while for high, centralization is the better option. Over-provision of public goods may result from strategic delegation by jurisdictions. Indeed, when the cost of public goods is shared among the members, policymakers have an incentive to delegate their bargaining power to individuals with a stronger preference for the public good. However, this last result is not unanimously shared in the literature on the relationship between centralization and delegation. For instance, Dur and Roelfsema (2005) or Lorz and Willmann (2005) conclude that under-provision of public goods can persist under centralization because policy makers delegate to agents with weaker preferences for public goods. ${ }^{3}$ In the International Environmental Agreements (IEAs) context,

\footnotetext{
${ }^{2}$ On one hand, Gradstein (2004) establishes a link between the Coase Theorem and Buchanan and Faith (1987) (which contains an error, see Rota Graziosi (2006)). The author explains how an egalitarian bargaining rule through referendum is necessary to extract the full benefits of centralization. On the other hand, Goyal and Staal (2004) analyse the effects of asymmetries among countries on political integration or separation. They show that the voting rule with two referenda (one in each region) is stable, in the sense that it is chosen by a vote following different rules as well as being normatively appealing.

${ }^{3}$ Dur and Roelfsema (2005) allow for costs which cannot be shared among districts, while Lorz and
} 
Buchholz, Haupt, and Peters (2005) establish that each individual delegates to a representative who is less "eco-friendly" than she is. Finally, Redoano and Scharf (2004) present delegation as a strategic tool to make policy coordination easier for the pro-centralization jurisdiction. These authors compare direct and representative democracy and establish that centralization is more likely to occur under representative democracy than under direct democracy. In a similar way, Laussel and Riezman (2005) who focus on international trade, emphasize that representative democracy leads to a more aggressive trade policy, i.e. a more protectionism than direct democracy. Here, we go a step further by assuming that the choice between these political regimes is endogenous.

The last strand of literature to which our paper is related considers strategic delegation in bargaining. ${ }^{4}$ Indeed, in line with Besley and Coate (2003), we consider political integration as a negotiation between sovereign states to provide a public good. But, we differ from these authors by formalizing the international negotiation through an asymmetric Nash Bargaining Solution (NBS). By definition, this solution is Pareto superior to the status quo, i.e. the decentralized equilibrium. The potential benefits of using delegates as credible commitment has already been highlighted by Schelling (1960). Since Crawford and Varian (1979) and Burtraw (1992), it has been recognized that misrepresentation might improve the players' negotiation position in a NBS. We observe a similar tendency and add to the results of Dur and Roelfsema (2005), Lorz and Willmann (2005) or Buchholz, Haupt, and Peters (2005): strategic delegation results in the choice of representatives with a lower preference for public spending, which gives a first bargaining advantage. We establish then that representative democracy is always preferred to the direct version: the median national voter chooses to have her hands tieds in order to get a bargaining advantage.

The original feature of our approach is to consider the constitutional design, more Willmann (2005) consider a continuum of local public goods with interregional spillovers.

4 Recent works, for instance Knight (2000), Messner and Polborn (2004), Harstad (2005) or Dal Bo (2006), consider supermajority requirements as a way for the median voter to delegate authority to someone different than himself. These authors show how externalities can be internalized by adjusting voting rules. We do not consider here this issue. 
precisely the identity and the "power" of the national representative, as endogenous, resulting from a majority vote in each country before any negotiation. Our approach complete the works of Besley and Coate (2003), Dur and Roelfsema (2005), Redoano and Scharf (2004), Lorz and Willmann (2005), Buchholz, Haupt, and Peters (2005)... by considering the degree of commitment which links each national representative to her constituents as a deliberative choice of the latter. As these authors, we observe some strategic delegation which affects the gain of political coordination. We deduce that an international treaty would be more efficient if it includes (and imposes) its ratification procedure, in this case a national referendum.

To establish these results, we develop a two-country model of choices for the provision of a unique public good with heterogeneous individuals and international policy spillovers. Following Segendorff (1998), ${ }^{5}$ we consider three distinct rules of delegation: strong, weak or none delegation. Our framework assumptions point unambiguously to an efficient centralization for the provision of the public good. However, we show that the populations decide to bind themselves by delegating the national policy decision to a "powerful conservative representative", ${ }^{6}$ in order to improve their bargaining situation. We emphasize that the benefit from coordination in terms of aggregate welfare vanishes as long as the delegation rule remains a national prerogative. Indeed, the noncooperative behaviours of countries when they choose their political representative and the competences of these latters, eliminate the gains from political integration.

We extend our model in two ways. First, we study whether a country prefers or not to initiate the political integration. We emphasize that countries are incited to follow the process in order to increase their negotiation power. The strategic pre-commitment which is induced by delegation, translates into a second-mover advantage. Secondly, we consider two domestic ratification procedures, which might improve the terms of political

\footnotetext{
${ }^{5}$ Segendorff (1998) does not consider voting behavior and the choice between different delegation rules is exogenous.

${ }^{6}$ A "powerful conservative representative" corresponds to a representative, who remains in place whatever the outcome of international negotiations and who is less keen on public spending than the median national voter. This notion will be formalized through the proposed framework in the next sections.
} 
integration by reducing the negative effect of strategic delegation. Note that we adopt a normative point of view in this second extension. Indeed, resorting to a referendum for a treaty ratification might be used strategically by one of the two countries. ${ }^{7}$ We consider only ratification procedures which would be imposed simultaneously to both countries. An ex ante referendum, which is assumed equivalent to a majority approval of political integration, leads to the rejection of any international treaty. On the other hand, an ex post referendum makes the international agreement possible and increases the aggregate welfare by reducing the negative effects of strategic delegations.

The remainder of the paper is organized as follows. Section 2 outlines the framework assumptions for our analysis. Section 3 then presents the negotiation game and two particular cases, which correspond to two Stackelberg games. Section 4 offers two extensions: the pre-play game and the two ratification procedures. Section 5 concludes.

\section{The model}

We model a world consisting of two countries (1 and 2), which might create a union. There is no mobility accross countries. We assume that the cost of providing the public good is not shared between participant countries. Some examples of these public goods are NATO's protection of Norway's ports, internal security, immigration policy (see Tabellini (2003)) or more broadly any international public goods, which is produced in a specific site and has no close substitutes in the other country. Following Hirshleifer (1983) and the literature concerning transnational public goods (see Kaul, Grunberg, and Stern (1999)), we may also interpret our assumption as the consequence of a specific aggregation technology (for instance: weakest-link or best-shot).

The asymmetry between the two countries which contrasts with Besley and Coate (2003)'s framework and its followers, enables us to distinguish the countries beyond their respective size, their incomes distribution or their distribution of the individual preferences

\footnotetext{
${ }^{7}$ For instance, studying the Amsterdam Intergovernmental Conference, Hug and König (2002) establish empirically that domestic constraints as referendum ratification influence the outcome of the bargaining process in accordance with Schelling's conjecture.
} 
for the public good. In accordance with Gradstein (2004), we assume that country 1 with a population normalized to 1 provides a public good, in quantity $g$, which generates externalities for the other country, namely country 2 , of size $d$, with $d \lessgtr 1$. Country 2 might pay a transfer, denoted by $T$, to country 1 in order to increase the production of the public good. The inhabitants of country 1 are assumed to have preferences that can be described by the following utility function:

$$
U\left(g, T ; a_{i}\right)=a_{i} g-e(g)+d T,
$$

where $a_{i}$ is the public good's appreciation for inhabitant $i$ in country 1 and $e(g)$ is the effort or the cost of producing the public good. For tractability, we consider a quadratic form of this effort: $e(g)=\frac{g^{2}}{2}$. In country 2 , we assume: ${ }^{8}$

$$
V\left(g, T ; b_{j}\right)=b_{j} g-T,
$$

where $b_{j}$ is the public good's appreciation for inhabitant $j$ in country 2 .

The paramaters $a_{i}$ and $b_{j}$ formalize the heterogenity of the countries' populations. By assumption, they are distributed over $[\underline{a}, \bar{a}]$ and $[\underline{b}, \bar{b}]$ with respect to the density function $h_{1}($.$) and h_{2}($.$) . Let A$ and $B$ denote the mean values of $a_{i}$ and $b_{j}$, whereas $A_{m}$ and $B_{m}$ will denote their median values. Therefore, we pose:

$$
\begin{gathered}
A_{m}-d B_{m} \geqslant \underline{a}, \\
A_{m}<A+d B .
\end{gathered}
$$

The first condition will insure that the application of the Median Voter Theorem (MVT) always yields to an interior solution in the sets $[\underline{a}, \bar{a}]$. The second will involve an underprovision of the public good under decentralization.

Whatever political integration occurs or not, the considered game is in three stages:

\footnotetext{
8 This formalisation is used by Gradstein (2004). It provides a very stylised (and tractable) representation of inter-jurisdictional policy spillovers.
} 
- Stage 1, constitutional design: the population of each country simultaneously chooses the kind of political representation it wants or, in other terms, the rule for delegation. ${ }^{9}$ Following Segendorff (1998), we consider three kinds of delegation: strong, weak or none. In the case of strong delegation, denoted by $s d$, the representatives choose their preferred policies. These policy-makers remain in place whatever the success or failure of negotiations. The second case, namely weak delegation and denoted by $w d$, involves a new round of elections if negotiations fail: the country's representative is compelled to go back to their voters in the case of failure. ${ }^{10}$ In the last case, the referendum denoted by ref, democracy is direct. Policies are then determined through a referendum, i.e. the country's median voters decide on policies. We assume then that at this step, each player has three available strategies, denoted by $x$, with $x \in\{s d, w d, r e f\}$.

- Stage 2, national representation: a simple majority vote fixes the identity of the political representative in each country (if, and only if, strong or weak delegation was chosen earlier). Each inhabitant of country 1, characterized by $a_{i}$, votes for her preferred representant, denoted by $a_{R}^{k}\left(. ; a_{i}\right)$, where $k \in\{N$, dec $\}$ states if political integration arises $(N)$ or not $(d e c)$. We assume a citizen-candidates model, where each candidate is an ordinary inhabitant of the country, who is solely motivated by her utility function. The set of available strategies for a voter in country 1 is given by $[\underline{a}, \bar{a}]$. In a similar way, we define $b_{R}^{k}\left(. ; b_{j}\right)$ the voting strategy of individual $b_{j}$ in country 2 , with $b_{R}^{k}\left(. ; b_{j}\right) \in[\underline{b}, \bar{b}]$.

- Stage 3, national policy: the countries' representatives (previously chosen) or a referendum settle the national policies: more accurately, the level of public good for country $1(g \geqslant 0)$ and the level of transfer paid by country $2(T \geqslant 0)$. These policies

\footnotetext{
${ }^{9}$ We assume that every delegation rule has the same cost.

${ }^{10}$ Note that the European Constitution referendum was an occasion for debates about the resignation of French President Chirac. In contrast, Luxembourg's Prime Minister, Junker, undertook to resign in the case of failure before the referendum result. In terms of our framework and under the assumption that the threat (or promise) to resign in the case of failure is credible, France was under strong delegation rule while Luxembourg opted for weak delegation.
} 
are determined noncooperatively in case of decentralization, while they are negotiated in case of international agreement. Given the assumption of our framework, separation corresponds to a free ride for country 2 . We formalize political integration by an asymmetric NBS as defined in Muthoo (1999), where the threat point is endogenous and corresponds to the noncooperative decentralized equilibrium.

Our formalization of political integration is closely related to the solution advanced by Buchholz, Haupt, and Peters (2005). Other alternatives of political integration have been proposed in the literature. Besley and Coate (2003) propose two specifications for an international legislature which determines the national policies: a noncooperative one where each country' representative has a probability $1 / 2$ of being the minimum winning coalition and of implementing her preferred policy; and a cooperative legislature which maximizes the surplus of both representatives. Ellingsen (1998) and Cheikbossian (2000) assume that a vote in both countries determines a unique representative (for instance, an European President). This solution would suppose the existence of a unique political decision-maker for the two countries, and so a deeper political integration than the one studied in this paper.

\subsection{Pareto optimum}

In order to contrast the positive predictions against a normative benchmark, we consider a Benthamite social welfare function, defined by:

$$
\begin{aligned}
W(g) & =\int_{\underline{a}}^{\bar{a}} U\left(g, T ; a_{i}\right) h_{1}\left(a_{i}\right) d a_{i}+d \int_{\underline{b}}^{\bar{b}} V\left(g, T ; b_{i}\right) h_{2}\left(b_{i}\right) d b_{i} \\
& =g\left(A+d B-\frac{g}{2}\right)
\end{aligned}
$$

The Pareto optimum over the two countries is determined by the following program: $g^{\text {opt }} \equiv \underset{g \geqslant 0}{\arg \max } W(g)$. The optimal levels of public good and welfare, respectively denoted 
by $g^{o p t}$ and $W^{o p t}$, are then given by:

$$
\begin{gathered}
g^{o p t}=A+d B \\
W^{o p t} \equiv W(A+d B)=\frac{1}{2}(A+d B)^{2} .
\end{gathered}
$$

At the Pareto optimum, the level of transfer is undetermined, since by the definition of our welfare function compensatory transfers are allowed between the two countries. ${ }^{11}$

\subsection{Decentralized equilibrium ${ }^{12}$}

The decentralized equilibrium is the status quo, which will be the threat point for the negotiations. It is defined by a noncooperative simultaneous subgame at the third stage of our general game, whatever the kind of delegation chosen at the second stage. Let $a_{R}$ and $b_{R}$ be the preference of the respective political representative in country 1 and in country 2. Applying backward induction, we determine the national policies, before we turn to the delegation issue. The national policies are given by the following system:

$$
\left\{\begin{array} { c } 
{ g ^ { \text { dec } } ( a _ { R } , b _ { R } ) \equiv \underset { g \geqslant 0 } { \operatorname { a r g } \operatorname { m a x } } \{ U ( g , T ; a _ { R } ) \} } \\
{ T ^ { \text { dec } } ( a _ { R } , b _ { R } ) \equiv \underset { T \geqslant 0 } { \operatorname { a r g } \operatorname { m a x } } \{ V ( g , T ; b _ { R } ) \} }
\end{array} \Leftrightarrow \left\{\begin{array}{c}
g^{\text {dec }}\left(a_{R}, b_{R}\right) \equiv g^{\text {dec }}\left(a_{R}\right)=a_{R} \\
T^{\text {dec }}\left(a_{R}, b_{R}\right) \equiv T^{\text {dec }}=0
\end{array}\right.\right.
$$

where the exponent dec informs us of the decentralized equilibrium values.

We now consider the second stage of the game, i.e. the choice of the country's representative. Under weak or strong delegation, the representative of country 1 is the unique relevant political decision-maker, since the decentralized equilibrium policies do not de-

\footnotetext{
${ }^{11}$ However, for instance, we might add an egalitarian rule, which gives the same utility for the mean inhabitant of both countries. Formally, the transfer, denoted $T^{e g}$, will then be the solution of:

$$
U\left(g^{o p t}, T^{e g} ; A\right)=V\left(g^{o p t}, T^{e g} ; B\right) \Leftrightarrow T^{e g}=\frac{(A+d B)[(2+d) B-A]}{2(1+d)} .
$$

This transfer is non negative if $\frac{A}{B}<2+d$.

12 The decentralized equilibrium corresponds in fact to the noncooperative equilibrium.
} 
pend on $b_{R}: g^{\text {dec }}\left(a_{R}\right)$ and $T^{d e c}$. Therefore, we have:

$$
a_{R}^{\text {dec }}\left(a_{i}\right) \equiv \underset{a_{R} \in[\underline{a}, \bar{a}]}{\arg \max }\left\{U^{\text {dec }}\left(a_{R} ; a_{i}\right)\right\} \Leftrightarrow a_{R}^{\text {dec }}\left(a_{i}\right)=a_{i} .
$$

By applying the MVT, we deduce that $a_{R}^{\text {dec }} \equiv a_{R}^{\text {dec }}\left(A_{m}\right)=A_{m}$ and then $g^{\text {dec }} \equiv g^{\text {dec }}\left(A_{m}\right)=$ $A_{m}$. Under decentralization, we observe that there is no strategic delegation: the representative of country 1 corresponds to the median voter of this country.

If national policies are determined directly through majority voting, they are the solution of the following system:

$$
\left\{\begin{array} { c } 
{ g ^ { \text { dec } } ( a _ { i } , b _ { i } ) \equiv \underset { g \geqslant 0 } { \operatorname { a r g } \operatorname { m a x } } \{ U ( g , T ; a _ { i } ) \} } \\
{ T ^ { \text { dec } } ( a _ { i } , b _ { i } ) \equiv \underset { T \geqslant 0 } { \operatorname { a r g } \operatorname { m a x } } \{ V ( g , T ; b _ { i } ) \} }
\end{array} \Leftrightarrow \left\{\begin{array}{c}
g^{\operatorname{dec}}\left(a_{i}, b_{i}\right) \equiv g^{\text {dec }}\left(a_{i}\right)=a_{i} \\
T^{\text {dec }}\left(a_{i}, b_{i}\right) \equiv T^{\text {dec }}=0
\end{array}\right.\right.
$$

Applying the MVT also yields to $g^{d e c}=A_{m}$. The first stage of the game is not relevant in the case of decentralization, since there is no strategic delegation, and then there is no difference between the three delegation rules. For any kind of delegation, the individual utilities values in both countries and the aggregate welfare are respectively given by:

$$
\begin{gathered}
U^{d e c}\left(A_{m} ; a_{i}\right) \equiv U\left(A_{m}, 0 ; a_{i}\right)=A_{m}\left(a_{i}-\frac{A_{m}}{2}\right) \\
V^{d e c}\left(A_{m} ; b_{i}\right) \equiv V\left(A_{m}, 0 ; b_{i}\right)=A_{m} b_{i} \\
W^{d e c} \equiv U^{d e c}\left(A_{m} ; A\right)+d V^{d e c}\left(A_{m} ; B\right)=A_{m}\left(A-\frac{A_{m}}{2}+d B\right) .
\end{gathered}
$$

Under condition (3) and according to the Oates Theorem, we note that decentralization involves an under-provision of the public good due to the presence of inter-jurisdictionnal spillovers. ${ }^{13}$ Moreover, it is obvious that the decentralized equilibrium aggregate welfare is always sub-optimal. ${ }^{14}$ Political integration allows countries to internalize some externali-

\footnotetext{
${ }^{13}$ If we link these distributions to the national income distributions, as in Bolton and Roland (1997), we note that $A_{m}<A$ and $B_{m}<B$ and we deduce that condition (3) is respected.

14 Indeed, we have:

$$
W^{o p t}-W^{d e c}=\frac{1}{2}\left(A-A_{m}+d B\right)^{2}>0
$$
}


ties and to fill part of the gap between the Pareto optimum and decentralized equilibrium. However, we will show in the next sections that the detail of political decision-making is not neutral and affects the degree to which the gap is filled.

\section{Nash Bargaining Solution}

In this section, we determine a perfect equilibrium in a negotiation game where the disagreement payoffs are endogenous, corresponding to the decentralized equilibrium. Since Binmore, Rubinstein, and Wolinsky (1986), the solution of any sequential bargaining problem à la Rubinstein, where parties alternate in making offers/counter-offers to the other party in order to reach an agreement, is the solution of a cooperative bargaining under appropriate formulation. More specifically, as the discount rate tends to zero, the perfect equilibrium converges to a NBS with the disagreement point being the payoff profile that prevails until the negotiating parties reach an agreement (see Muthoo (1999)).

We denote by $a_{R^{\prime}}$ the preference of the political representative in country 1 when negotiations fail. The value of $a_{R^{\prime}}$ depends on the delegation' rule chosen at the first stage. We have: $a_{R}=a_{R^{\prime}}$ in the case of strong delegation (the success or failure of the political integration does not affect the identity of the political representative); $a_{R^{\prime}}=A_{m}$ in the case of weak delegation (if negotiations for political integration fail, a new election in each separate country fixes on the identity of the representative, who will be the median national voter as in the decentralized situation); and $a_{R}=a_{R^{\prime}}=A_{m}$ in the case of a referendum (no delegation).

Whatever the delegation rule in each country, the set of possible agreements is given by $\Psi \equiv\left\{(g, T) \in \mathbf{R}^{2+}: g \geqslant 0\right.$ and $\left.T \geqslant 0\right\}$. If the countries fail to reach agreement, they obtain the decentralized outcome, denoted by $\Phi \equiv\left(U^{\text {dec }}\left(a_{R^{\prime}} ; a_{R}\right), V^{\text {dec }}\left(a_{R^{\prime}} ; b_{R}\right)\right)$, where the utilities values are respectively given by $(7)$ and (8). Let $\left(g^{N}\left(a_{R^{\prime}}, a_{R}, b_{R}\right), T^{N}\left(a_{R^{\prime}}, a_{R}, b_{R}\right)\right)$ 
denote the NBS of the problem $(\Psi, \Phi)$, we have:

$$
\left(g^{N}(.), T^{N}(.)\right) \equiv \underset{(g, T) \in \Psi}{\arg \max }\left\{\left[U\left(g, T ; a_{R}\right)-U^{\text {dec }}\left(a_{R^{\prime}} ; a_{R}\right)\right]^{\alpha}\left[V\left(g, T ; b_{R}\right)-V^{\text {dec }}\left(a_{R^{\prime}} ; b_{R}\right)\right]^{1-\alpha}\right\},
$$

where $\alpha$ is the relative bargaining power of country 1 . Remark that in the non-degenerate NBS problem, the following conditions must also hold:

$$
U\left(g, T ; a_{R}\right)>U^{\operatorname{dec}}\left(a_{R^{\prime}} ; a_{R}\right) \text { and } V\left(g, T ; b_{R}\right)>V^{\operatorname{dec}}\left(a_{R^{\prime}} ; b_{R}\right) .
$$

The equilibrium values of $g$ and $T$ are then implicitly characterized by the following system of First Order Conditions (FOCs):

$$
\left\{\begin{array}{l}
\alpha \frac{\partial U(.)}{\partial g}\left(V\left(g, T ; b_{R}\right)-V^{\operatorname{dec}}\left(a_{R^{\prime}} ; b_{R}\right)\right)+(1-\alpha) \frac{\partial V(.)}{\partial g}\left(U\left(g, T ; a_{R}\right)-U^{\operatorname{dec}}\left(a_{R^{\prime}} ; a_{R}\right)\right)=0 \\
\alpha \frac{\partial U(.)}{\partial T}\left(V\left(g, T ; b_{R}\right)-V^{\operatorname{dec}}\left(a_{R^{\prime}} ; b_{R}\right)\right)+(1-\alpha) \frac{\partial V(.)}{\partial T}\left(U\left(g, T ; a_{R}\right)-U^{\operatorname{dec}}\left(a_{R^{\prime}} ; a_{R}\right)\right)=0
\end{array}\right.
$$

The unique solution of (12) satisfying (11) is then given by:

$$
\left\{\begin{array}{c}
g\left(a_{R}, b_{R}\right)=a_{R}+d b_{R} \\
T\left(a_{R^{\prime}}, a_{R}, b_{R}\right)=\frac{a_{R}-a_{R^{\prime}}+d b_{R}}{2 d}\left((1-\alpha)\left(a_{R^{\prime}}-a_{R}\right)+(1+\alpha) d b_{R}\right)
\end{array}\right.
$$

By substituting (13) in (1) and (2), we obtain:

$$
\begin{gathered}
U\left(g^{N}(.), T^{N}(.) ; a_{i}\right)=\frac{1}{2}\left[\begin{array}{c}
\left(a_{R}+d b_{R}\right)\left(2 a_{i}-(2-\alpha) a_{R}+\alpha d b_{R}\right) \\
+a_{R^{\prime}}\left(2 a_{R}-(1-\alpha) a_{R^{\prime}}-2 \alpha\left(a_{R}+d b_{R}\right)\right)
\end{array}\right] \\
V\left(g^{N}(.), T^{N}(.) ; b_{i}\right)=b_{i}\left(a_{R}+d b_{R}\right)+\frac{\left(a_{R}+d b_{R}-a_{R^{\prime}}\right)}{2 d}\left[\begin{array}{c}
(1-\alpha)\left(a_{R}-a_{R^{\prime}}\right) \\
-(1+\alpha) d b_{R}
\end{array}\right]
\end{gathered}
$$

We now consider the second stage of the game: the choice of political representative in each country. Note that $\frac{d a_{R^{\prime}}}{d a_{R}}=1$ in the case of strong delegation since $a_{R}=a_{R^{\prime}}$, and 
$\frac{d a_{R^{\prime}}}{d a_{R}}=0$ for weak delegation. ${ }^{15}$ By definition, under the referendum rule, there is no election of the political representative. The policy variables $(g$ and $T)$ are then chosen directly by the inhabitants. We present these developments in ApPEndix A1.

The first stage of the game concerns the choice of the delegation rule, which corresponds to a simultaneous move for each player. Each country has three pure strategies available: strong delegation $(s d)$, weak delegation $(w d)$ and referendum $(r e f)$. Let $x$ define the strategy of country 1 and $y$ the strategy of country 2 , with $(x, y) \in\{s d, w d, r e f\} \times$ $\{s d, w d, r e f\} .{ }^{16}$ From Appendix A1, we show that weak delegation is not relevant in this game for country 2. Indeed, weak delegation and referendum in this country yield to identical results. ${ }^{17}$ The normal form of the game is given by:

\section{Insert Table 1.}

We deduce the following proposition:

Proposition 1 Under the assumptions of our framework,

(i) the unique Subgame Perfect Nash Equilibrium involves strong delegation in both countries, $(s d, s d)$;

(ii) political integration does not improve aggregate welfare with respect to decentralization $\left(W^{N}(s d, s d)=W^{d e c}\right)$.

\section{Proof: see Appendix A1.}

The first result of Proposition 1 is an illustration of the paradox of weakness emphasized by Schelling (1960). ${ }^{18}$ Each country looks to improve its negotiation position

\footnotetext{
${ }^{15}$ In ApPEndix A.1, we establish the strictly concavity of $U\left(g^{N}\left(a_{R}, b_{R}\right), T^{N}\left(a_{R^{\prime}}, a_{R}, b_{R}\right) ; a_{i}\right)$ and $V\left(g^{N}\left(a_{R}, b_{R}\right), T^{N}\left(a_{R^{\prime}}, a_{R}, b_{R}\right) ; b_{i}\right)$ with respect to $a_{R}$ and $b_{R}$.

16 If one or both countries chooses to decide its policy through a referendum at the first stage of the game, it seems unrealistic to imagine a negotiation between the population and the possible political representative in the other country. That is the reason why we assume that there is a "fictitious" delegation in which the representative corresponds exactly to the median voter. This hypothesis is equivalent to that of sincere voting. Like Laussel and Riezman (2005), we might also assume that only the candidates motivated by winning the elections commit themselves to the ideal policy of the median voter.

17 Outside options are identical under weak delegation and no delegation.

18 This author wrote on page 22:
}

"the power to constrain an adversary may depend on the power to bind oneself; that, in bargaining, weakness is often strength, freedom may be freedom to capitulate, and to burn bridges behind one may suffice to undo an opponent." 
by two means: the kind of delegation which settles the domestic power of the political representative and the identity of the political representative. At the equilibrium, both countries choose a "powerful conservative representative": voters opt for strong delegation $(s d, s d)$ and they strategically delegate to representatives who are more averse to public spending than they are. ${ }^{19}$ Strong delegation is here a credible strategic commitment. ${ }^{20} \mathrm{By}$ choosing this delegation rule, populations bind themselves in order to improve their initial bargaining situation. We note that the equilibrium level of public good does not depend on the relative bargaining power of country $1(\alpha)$, while the transfer paid by country 2 to country 1 is decreasing in this parameter. The more powerfull country 1 is, the less will be the level of transfer paid by country $2\left(\frac{\partial T^{N}(\cdot)}{\partial \alpha}<0\right)$. This paradoxical result is explained by the Schelling conjecture. Through our framework, the vote for a more conservative representative is the second means of making the other country bear the cost of the public good as in any prisoner's dilemma. Like Lorz and Willmann (2005), we observe under condition (3) that strategic delegation systematically involves an under-provision of the public good $\left(g^{N}(s d, s d)=A_{m}=g^{d e c}<g^{o p t}=A+d B\right)$.

Since the equilibrium transfer $T^{N}$ is here strictly positive and the level of public good is the same as the decentralized level $\left(g^{N}(s d, s d)=A_{m}\right)$, we deduce that country 2 is worse-off as soon as political integration is considered. Indeed, strong delegation in country 1 involves a provision of public good in the case of no agreement inferior to the level provided in the case of separation: $g^{d e c}(s d, s d)=A_{m}-\frac{1}{1+\alpha} d B_{m}<g^{d e c}=A_{m}$. In other words, the political integration process ensures that country 1 will improve its situation at the expense of country 2 by threatening to reduce the level of public good through the identity and the power of its political representative.

The second result of Proposition 1 establishes the absence of any gain in the international negotiation at the aggregate level. Not only, does political integration not allow the countries to reach the Pareto optimum, it also does not increase the aggre-

\footnotetext{
${ }^{19} a_{R}^{N}\left(x, y ; a_{i}\right)$ and $b_{R}^{N}\left(x, y ; b_{j}\right)$ are the ideal representative for individual of type $a_{i}$ in country 1 and $b_{j}$ in country 2. From (17) in APPEndix A.1, we observe that: $a_{R}^{N}\left(s d, s d ; a_{i}\right)=a_{i}-\frac{1}{1+\alpha} d b_{R}<a_{i}$ and $b_{R}^{N}\left(s d, s d ; b_{j}\right)=\frac{1}{1+\alpha} b_{j} \leqslant b_{j}$.

20 The credibility of our equilibrium corresponds to its subgame perfectness.
} 
gate welfare with respect to decentralization (see ApPEndix A.1). Our result contrasts with Gradstein (2004) who assumes uniform preferences distributions in both countries. ${ }^{21}$ However, it is similar to the conclusion of Buchholz, Haupt, and Peters (2005) who focus on IEAs. These authors show that political integration might increase ecological damages in comparison with the status quo due to the strategic delegation' behaviors. They deduce that no agreement might be preferable. As an extreme case of Dur and Roelfsema (2005)'s framework, our model yields a similar conclusion. The case (ref, ref) where no delegation is possible, yields the maximum aggregate welfare (see ApPEndix A1). The second part of the following section will examine some additional elements in the design of international treaties that might improve the payoffs of political integration by moving the equilibrium closer to the case (ref, ref).

At the equilibrium, we observe that no country choose direct democracy. The European Union (EU) has often been accused of a "democratic deficit". Although there is no single meaning for this latter expression, Follesdal and Hix (2006) propose a synthetic approach to recents studies on this issue. Among different elements, such as the European Parliament's weakness or the absence of European elections, one of the key features of the "democratic deficit" is the gap, the "policy drift", between the will of national majorities and the policies implemented at the European level. The EU seems to adopt policies that are not supported by national majorities, and the EU policy outcomes are accused of differing perceptibly from those preferred by national majorities. Through an empirical investigation, Alesina, Angeloni, and Schuknecht (2005) show that the allocation of EU policy prerogatives deviates from the distribution which would be desired by European inhabitants. ${ }^{22}$ Proposition 1 presents this European "democratic deficit" as a delib-

\footnotetext{
${ }^{21}$ Even if $A=A_{m}$ and $B=B_{m}$, we do not observe that $W^{N}(s d, s d)=W^{o p t}$, since the non-cooperative strategies of delegation affect the final result.

${ }^{22}$ In fact, Alesina, Angeloni, and Schuknecht (2005) define normative criteria for an optimal share of policy-making between national governments and EU level. However, they notice (page 287):
}

"In summary, the evidence from the Eurobaromater shows that the preferences of European citizens regarding the allocations of functions between Europe and member countries is remarkably similar to our judgement based on the predictions of theoretical models (a partial exception is Regional aid)." 
erate choice made by national populations. Indeed, direct democracy (or referendum) is never chosen as the equilibrium political regime. Accordingly to the Schelling conjecture, national populations opt for strategically delegating to a representative less in favor of the public good, and thus more reluctant to centralize, in order to improve their bargaining position.

Now, we consider two particular cases of the NBS, where the negotiating power $(\alpha)$ is equal to 1 or to 0 . The Stackelberg 1 game $^{23}$ corresponds to the case where country 1 has the political integration' initiative $(\alpha=1)$. It makes an offer in term of national policies $(g$ and $T$ ) at the third stage of the game; country 2 accepts and political integration occurs, or it rejects and remains separate. Everything happens as if country 1 is the leader of a classic Stackelberg game. In this scenario, country 1 has the agenda-setting power. In the second case, named Stackelberg 2, the sequence of the moves is inverse, country 2 playing first $(\alpha=0)$. These two games are named the "take-it-or-leave-it" option. The leader is able to make an offer to the follower such that the latter is indifferent between political union or separation. This exercise allows us to consider a hegemonic country, which bears the production of the international public good. By comparing the equilibriums of the two Stackelberg games, the following corollary is immediate:

Corollary 1 Given the equilibriums in the two Stackelberg games, no country wishes to be the first mover, i.e. to take the initiative of political integration.

Proof: From Table 1 with $\alpha=1$ and $\alpha=0$, we deduce that:

$$
\left\{\begin{array}{c}
U^{1}(s d, s d)=\frac{1}{2} A_{m}^{2}+\frac{1}{4} d^{2} B_{m}^{2}<U^{2}(s d, s d)=\frac{1}{2} A_{m}^{2}+\frac{1}{2} d^{2} B_{m}^{2} \\
V^{1}(s d, s d)=A_{m} B_{m}-\frac{1}{4} d B_{m}^{2}>V^{2}(s d, s d)=A_{m} B_{m}-\frac{1}{2} d B_{m}^{2}
\end{array}\right.
$$

where $U^{i}(.,$.$) and V^{i}(.,$.$) denote the equilibrium values at the Stackelberg game, where$ country $i$ is the leader.

Each country prefers to be follower in the Stackelberg game. The player making the offer cannot capture the surplus from an immediate agreement, since the follower would delegate to a representative with a lesser preference for the public good. We will go into this point in greater depth in the following section.

\footnotetext{
23 This scenario might be considered as an immediate extension of Gradstein (2004).
} 


\section{Extensions}

In this section we propose two extensions of the preceding game. The first one consists in allowing countries to initiate or not the political integration process. In fact, we assume that countries decide their role as first or second mover in a pre-play game. The second extension examines the effect of a ratification requirement on political integration. We consider two forms of ratification: an informal procedure, which actually corresponds to an ex ante approval of political integration, and a formal ratification which is equivalent to an ex post referendum.

\subsection{Choosing roles}

In the context of competition between firms, the literature has studied the premise that the order of play in a given two-player game ought to result from the players' own preplay timing decisions. The determination of simultaneity versus sequentiality of moves, as well as the assignment of roles of the players in the latter case, is then completely endogenous (cf. d'Aspremont and Gerard-Varet (1980), Gal-Or (1985) or Dowrick (1986)). We consider here a pre-play game at a stage 0 , where each country's median voter announces independently her choice of role, as leader or follower. Each country has two possible strategies: Leads or Follows. In the same way as Dowrick (1986), we assume that if country $i$ chooses leadership (strategy Leads), it commits itself to setting its national policy as leader and if it chooses to be a follower (Follows), it commits itself to following the other country's decision. If countries choose complementary roles, one of the two Stackelberg games will emerge. If both choose to lead, we assume that there is a negotiation between them, which corresponds to the NBS. However, if both countries choose to follow, each waits for a proposition from the other. We then assume that there is no political integration and countries receive their decentralized outputs. We deduce 
the following normal form for the meta-game: ${ }^{24}$

\section{Insert Table 2}

We obtain the Proposition 2:

Proposition 2 The unique Subgame Perfect Nash Equilibrium (SPNE) of the game described in Table 4 is (Leads, Follows), which corresponds to the equilibrium of the Stackelberg 1 game (i.e. the NBS with $\alpha=1$ ).

Proof: From TABle 2, it is obvious that for country 2, the strategy Leads is always dominated by the strategy Follows. We deduce our result.

Assuming countries' populations are able to choose through a majority vote whether they will initiate political integration or not, we conclude that the country which provides the public good, namely country 1, prefers to play first while the second country follows. As has been shown in section 3, this equilibrium is sub-optimal. The Schelling conjecture might also apply here: the leader is constrained by the participation of the follower; aware of her power on the final negotiation, the follower improves her bargaining position to the detriment of the leader. By comparing Proposition 2 to Corollary 1, we deduce that the threat of the status quo is more restrictive for country 1, which accepts the leader position. Indeed, country 2 is always able to free ride on the public good provision from country 1 in the case of separation.

\subsection{Ratification requirement}

In the Proposition 1, we establishes that political integration does not increase the level of the provided public good with respect to its decentralized level. In this subsection, our approach is more normative by examining whether a ratification procedure would improve the aggregate welfare. ${ }^{25}$ Here, we study the effects of a ratification requirement through a referendum on the political integration issue. We do not consider the strategic use of

\footnotetext{
${ }^{24}$ We denote $U^{i}(s d, s d)$ and $V^{i}(s d, s d)$ the equilibrium utilities of the median voter when country $i$ plays first $(i=1,2)$.

${ }^{25}$ The analysis of tactical commitments through ratification procedures would be very interesting, but would require substantial developments.
} 
ratification requirements, i.e. the cases where each country looks to increase its bargaining power by binding itself through a ratification.

Since Putnam (1988), a distinction has been made between formal ratification and more informal forms of approval. We assume that the sequence of decisions is the crucial difference between formal and informal ratification. We focus on both forms of ratification: the informal procedure corresponds to an approval of the process of political integration at the beginning of the game, while formal ratification is achieved through a referendum on the negotiated national policies $(g$ and $T)$ at the end of the game.

\subsubsection{Informal ratification}

Informal ratification is particularly important in the European Union context, since populations' control over policy is usually indirect when it exists. Instead of describing informal ratification through some consultative costs which governments have to bear, we prefer to define informal ratification as an ex ante referendum. We then imagine an additional stage (stage 0) at the beginning of the game developped in Section 3, where a referendum is held on the political integration issue in each country. By backward induction, we have only to establish if median national voters are in favor of political integration or not at the Perfect Nash Equilibrium established in Proposition 1. The result is obvious by comparing the utility levels at the equilibrium given in Table 1 with those at the decentralized equilibrium, whatever is the value of $\alpha$ belonging to $[0,1]$. We deduce the following proposition:

Proposition 3 Under the assumptions of our framework, an informal ratification, which corresponds to a referendum on political integration at the beginning of the game, would always lead the populations to reject political integration.

Proof: using Table 1, we deduce that:

$$
\begin{aligned}
U^{N}(s d, s d) & =\frac{1}{2} A_{m}^{2}+\frac{1}{2(1+\alpha)} d^{2} B_{m}^{2}>U^{d e c}\left(A_{m} ; A_{m}\right)=\frac{A_{m}^{2}}{2} \\
V^{N}(s d, s d) & =A_{m} B_{m}-\frac{1}{2(1+\alpha)} d B_{m}^{2}<V^{d e c}\left(A_{m} ; B_{m}\right)=A_{m} B_{m} .
\end{aligned}
$$


The political integration process would fail if an informal ratification is proved indispensable. This result is an immediate consequence of Proposition 1. Indeed, we have established that the equilibrium transfer $T^{N}$ is strictly positive, while the level of public good remains the same as at the decentralized equilibrium $\left(g^{N}(s d, s d)=A_{m}\right)$. By considering political integration, country 1 forces country 2 to finance part of the cost of the public good. In another perspective, country 2 is not any more able to free ride as soon as political integration negotiations begin.

\subsubsection{Formal ratification}

We now consider formal ratification, which corresponds to a referendum at the end of the game. We assume that a clause is introduced into the international treaty, which imposes formal ratification through a referendum on each participant country. We restrict our analysis to the symmetric case only: after an agreement is reached, a referendum on the negotiated national policies is held in both countries. The last stage of our game is modified and the maximization program (10) becomes constrained. Let $\left(g_{\text {Rat }}^{N}(),. T_{\text {Rat }}^{N}().\right)$ denote the equilibrium value of the constrained maximization program:

$$
\begin{gathered}
\left(g_{\text {Rat }}^{N}(.), T_{\text {Rat }}^{N}(.)\right) \equiv \underset{(g, T) \in \Psi}{\arg \max }\left\{\left[U\left(g, T ; a_{R}\right)-U^{\text {dec }}\left(a_{R^{\prime}} ; a_{R}\right)\right]^{\alpha}\left[V\left(g, T ; b_{R}\right)-V^{\text {dec }}\left(a_{R^{\prime}} ; b_{R}\right)\right]^{1-\alpha}\right\} \\
\text { s.t. }\left\{\begin{array}{l}
U\left(g, T ; A_{m}\right) \geqslant U^{\text {dec }}\left(a_{R^{\prime}} ; A_{m}\right) \\
V\left(g, T ; B_{m}\right) \geqslant V^{\text {dec }}\left(a_{R^{\prime}} ; B_{m}\right)
\end{array}\right.
\end{gathered}
$$

We deduce the following Lagrangian function:

$$
\begin{gathered}
L(g, T ; \lambda, \mu)=\left[U\left(g, T ; a_{R}\right)-U^{\operatorname{dec}}\left(a_{R^{\prime}} ; a_{R}\right)\right]^{\alpha}\left[V\left(g, T ; b_{R}\right)-V^{\operatorname{dec}}\left(a_{R^{\prime}} ; b_{R}\right)\right]^{1-\alpha} \\
-\lambda\left[U\left(g, T ; A_{m}\right)-U^{\operatorname{dec}}\left(A_{m} ; A_{m}\right)\right]-\mu\left[V\left(g, T ; B_{m}\right)-V^{\operatorname{dec}}\left(A_{m} ; B_{m}\right)\right]
\end{gathered}
$$

For each delegation rule, we consider four cases depending on the values of the Lagrange multipliers: $\lambda(>0$ or $=0)$ and $\mu(>0$ or $=0)$. We obtain the following normal form of 
the modified game (see developments in APPENDix A.3):

\section{Insert Table 3}

We deduce the following proposition:

Proposition 4 Under the assumptions of our framework, formal ratification on the international treaty through an ex post referendum yields to:

(i) the SPNE: (wd, sd);

(ii) an increase of aggregate welfare with respect to decentralization $\left(W^{N}(w d, s d)>W^{d e c}\right)$.

Proof: see Appendix A.3.

Formal ratification restrains the harmful delegation in country 1 , since the equilibrium strategy, weak delegation $(w d)$, involves by definition at least the satisfaction of the median voter. In the same way as without ratification constraints, we notice that the utility of the median voter in country 1 remains decreasing in $\alpha$, the bargaining power of this country. Our result contrasts sharply with Redoano and Scharf (2004), who establish that delegation can make centralization possible in situations where a referendum would not support it. However, these authors assume a polar situation where the heterogeneity of the population is represented by a couple of real values. Therefore, in their framework, the strategic delegation is very restricted since there are only two possible types of representatives. Moreover, following Besley and Coate (2003), Redoano and Scharf (2004) formulate political centralization as a gamble where each national representative has a probability (one in two) of being the unique relevant decision maker for the countries' union. There is no bargaining between the representatives.

By comparing the welfare equilibriums with and without a formal ratification requirement, we establish that the median voter of country 1 is worse off, while the median voter of country 2 enjoys an improvement of her (his) utility. ${ }^{26}$ At the equilibrium, the

\footnotetext{
${ }^{26}$ We observe that: $\left.\forall \alpha \in\right] 0,1[$,

$$
U_{R a t}^{N}(w d, s d)=\frac{1}{2} A_{m}^{2}+\frac{2-\alpha}{8} d^{2} B_{m}^{2}<U^{N}(s d, s d)=\frac{1}{2} A_{m}^{2}+\frac{1}{2(1+\alpha)} d^{2} B_{m}^{2}
$$$$
V_{R a t}^{N}(w d, s d)=A_{m} B_{m}+\frac{1+\alpha}{8} d B_{m}^{2}>V^{N}(s d, s d)=A_{m} B_{m}-\frac{1}{2(1+\alpha)} d B_{m}^{2} .
$$ 
agregate welfare remains lower than the Pareto optimum, but it is better than the decentralized level if the distributions of the individual preferences for the public good respect condition (3).

From Propositions 3 and 4, a second corollary is immediate:

Corollary 2 Under the assumptions of our framework, the informal ratification game has a smaller core than the formal.

In other words, agreement may be possible under a formal ratification but impossible under an informal one. Thus, the timing of majority approval matters.

Before concluding, we go back to the European Constitution. Beyond the determination of the political representatives who will negotiate the international agreement, we have proposed two types of ratification procedure in this subsection: a formal and an informal. We establish in PROPOSITION 4 that the formal ratification yields to a welfareenhancing agreement, while the informal one induces the status quo, i.e. separation. In the light of this last result, a procedure, which would impose treaty's ratification through an ex post referendum, might be added to the political integration process. It is then efficient to associate union with the acceptance of such a ratification procedure. The sovereignty of states does not seem violated, since the initiative for political integration remains a national competence.

\section{Concluding remarks}

We have studied political centralization in a two-country model with heterogenous policy preferences and international spillovers when the constitutional design is endogenous. Under the restrictive assumptions of our framework, we have established that countries' inhabitants always prefer representative democracy, more accurately, strong delegation, in order to ensure a strategic pre-commitment and reinforce their bargaining power. Moreover, we show that populations delegate strategically to representatives who are less keen on public goods than the country's median voter. These behaviors imply an inefficient political integration. Indeed, the choice of delegation rule and the identity of the political 
representatives generate negative political externalities between countries, which cancel the internalization of economic externalities (resulting from the centralized provision of the public good). We have also observed that no country chooses to initiate political integration, since the follower takes an advantage coming from its participation constraint. By considering a pre-play game, we have established that the option to strategically delegate integration decisions to an elected representative translates into a second-mover advantage. The SPNE corresponds to the case where the country which produces the public good proposes political integration and the country which pays a transfer remains indifferent between the status quo and integration. We concluded our analysis by considering two forms of ratification process. An ex ante ratification, which corresponds to a referendum before international negotiations, prevents any treaty. In contrast, a formal ratification procedure, equivalent to an ex post referendum, would substantially improve the result of political integration by restraining the strategic delegations.

The simplicity of our framework imposes several restrictions. One of them is the sitespecific nature of the considered public good. An immediate development would be to assume two public goods, one in each country. This would allow us to be closer to Besley and Coate (2003) and their followers. Another weakness is the assumption of perfect information on the individual preferences. However, our results bear out the analysis of Zantman (1998), who establishes that, in the presence of informational imperfections on preferences for the public good, strategic delegation decreases welfare with respect to direct democracy. Finally, a substantial limit of our framework is the one-dimensional nature of the political integration, one public good and one transfer. Thus, in contrast to Lorz and Willmann (2005), the political integration decision remains a binary choice and a further development would be to analyse how the delegation rule would affect the equilibrium degree of political integration. 


\section{References}

Alesina, A., I. Angeloni, and L. Schuknecht (2005): "What does the European do?," Public Choice, 123(3-4), 275-319.

Alesina, A., and E. Spolaore (1997): "On the Number and Size of Nations," Quarterly Journal of Economics, 112(4), 1027-1056.

(2003): The Size of Nations. MIT Press, Cambridge, Massachusetts.

Besley, T., and S. Coate (2003): "Centralized versus Decentralized Provision of Local Public Goods: a Political Economy Approach," Journal of Public Economics, 87(12), 2611-2637.

Binmore, K., A. Rubinstein, and A. Wolinsky (1986): "The Nash Bargaining Solution in Economic Modelling," Rand Journal of Economics, 17(2), 176-188.

Bolton, P., and G. Roland (1997): "The Break-Up of Nations: A Political Economy Analysis," Quarterly Journal of Economics, 112(4), 1057-1090.

Buchanan, J. M., and R. L. Faith (1987): "Secession and the Limits of Taxation: Towards a Theory of Internal Exit," American Economic Review, 77(5), 1023-1031.

Buchholz, W., A. Haupt, and W. Peters (2005): "International Environmental Agreements and Strategic Voting," Scandinavian Journal of Economics, 107(1), $175-195$.

Burtraw, D. (1992): "Strategic delegation in bargaining," Economics Letters, 38(2), $181-185$.

Cheikbossian, G. (2000): "Federalism, Distributive Politics and Representative Democracy," Economics of Governance, 1, 105-122.

Crawford, V., and H. R. Varian (1979): "Distortion of Preferences and the Nash Theory of Bargaining," Economic Letters, 3, 203-206.

DAL Bo, E. (2006): "Committees with supermajority voting yield commitment with flexibility," Journal of Public Economics, 90(4-5), 573-599.

D'Aspremont, C., And L.-A. Gerard-Varet (1980): "Stackelberg-Solvable Games and Pre-Play Communication," Journal of Economic Theory, 23(2), 201-217.

Dowrick, S. (1986): "von Stackelberg and Cournot Duopoly: Choosing Roles," Rand Journal of Economics, 17(2), 251-260.

Dur, R. A., And H. J. Roelfsema (2005): "Why does Centralisation fail to internalise Policy Externalities?," Public Choice, 122(3-4), 395-416.

Ellingsen, T. (1998): "Externalities vs Internalities: a Model of Political Integration," Journal of Public Economics, 68(2), 251-268. 
Follesdal, A., And S. Hix (2006): "Why There is a Democratic Deficit in the EU: A Response to Majone and Moravcsik," Journal of Common Market Studies, 44(3), forthcoming.

GaL-OR, E. (1985): "First Mover and Second Mover Advantages," International Economic Review, 26(3), 649-653.

Goyal, S., and K. StaAl (2004): "The Political Economy of Regionalism," European Economic Review, 48(3), 563-593.

Gradstein, M. (2004): "Political Bargaining in a Federation: Buchanan Meets Coase," European Economic Review, 48(5), 983-999.

Harstad, B. (2005): "Majority Rules and Incentives," The Quarterly Journal of Economics, 120(4), 1535-1568.

Hirshleifer, J. (1983): "From Weakest-Link to Best-Shot: The Voluntary Provision of Public Goods," Public Choice, 41, 371-386.

Hug, S., And T. KÖNIG (2002): "In View of Ratification: Governmental Preferences and Domestic Constraints at the Amsterdam Intergovernmental Conference," International Organization, 56(2), 447-476.

Kaul, I., I. Grunberg, and M. Stern (1999): Global Public Goods - International Cooperation in the 21st Century. Oxford University Press, New York.

Knight, B. G. (2000): "Supermajority Voting Requirements for Tax Increases: Evidence from the States," Journal of Public Economics, 76(1), 41-67.

Laussel, D., and R. Riezman (2005): "The Sources of Protectionist Drift in Representative Democracies," European Economic Review, 49(7), 1855-1876.

Lockwood, B. (2002): "Distributive Politics and the Cost of Centralization," Review of Economic Studies, 69(2), 313-337.

Lorz, O., and G. Willmann (2005): "On the Endogenous Allocation of Decision Powers in Federal Structures," Journal of Urban Economics, 57(2), 242-257.

Messner, M., and M. K. Polborn (2004): "Voting on Majority Rules," Review of Economic Studies, 71(1), 115-132.

Muthoo, A. (1999): Bargaining Theory with Applications. Cambridge University Press, Cambridge, UK.

OAtes, W. (1972): Fiscal Federalism. Harcourt Brace, New York.

Persson, T., and G. Tabellini (1995): "Double-edged incentives: Institutions and policy coordination," in Handbook of International Economics, ed. by G. M. Grossman, and K. Rogoff.

Putnam, R. D. (1988): "Diplomacy and domestic politics: the logic of two level games," International Organization, 42(3), 427-460. 
Redoano, M., And K. A. Scharf (2004): "The Political Economy of Policy Centralization: Direct versus Representative Democracy," Journal of Public Economics, 88(3-4), 799-817.

Rota Graziosi, G. (2006): "The Theory of 'Internal Exit', a Comment on Buchanan and Faith (1987)," American Economic Review, Forthcoming.

RutA, M. (2005): "Economic Theories of Political (Dis)integration," Journal of Economic Surveys, 19(1), 1-21.

Schelling, T. (1960): The Strategy of Conflict. Harvard University Press, Cambridge, MA.

SegendorfF, B. (1998): "Delegation and Threat in Bargaining," Games and Economic Behavior, 23(2), 266-283.

Tabellini, G. (2003): "Principles of Policymaking in the European Union: an Economic Perspective," Levine's working paper archive, UCLA Department of Economics.

Zantman, W. (1998): "Délégation stratégique et choix constitutionnel," Revue d'Economie Politique, 110(5), 683-700.

\section{A Appendix}

\section{A.1 Nash Bargaining Solution}

We define $a_{R}^{N}\left(x, y ; a_{i}\right)$ and $b_{R}^{N}\left(x, y ; b_{i}\right)$ the ideal representative for individual of type $a_{i}$ in country 1 and $b_{i}$ in country 2 , in case of the delegation rules $(x, y)$ in both countries. In the same way, we denote by $g^{N}(x, y), T^{N}(x, y), U^{N}(x, y), V^{N}(x, y)$ and $W^{N}(x, y)$ the equilibrium values of the public good's quantity, the transfer, the utilities and the aggregate welfare for a couple of strategies $(x, y)$. Note that the utility functions $U\left(g^{N}(),. T^{N}(.) ; a_{i}\right)$ and $V\left(g^{N}(),. T^{N}(.) ; b_{j}\right)$ are strictly concave with respect to $a_{R}$ and $b_{R}$. Since $\frac{\partial a_{R^{\prime}}}{\partial a_{R}} \in\{0,1\}$ and $\frac{\partial a_{R^{\prime}}^{2}}{\partial^{2} a_{R}}=0$, we have:

$$
\begin{aligned}
& \frac{\partial^{2} U\left(g^{N}(.), T^{N}(.) ; a_{i}\right)}{\partial a_{R}^{2}}=-2+\alpha+(1-\alpha)\left(2-\frac{\partial a_{R^{\prime}}}{\partial a_{R}}\right) \frac{\partial a_{R^{\prime}}}{\partial a_{R}}<0, \\
& \frac{\partial^{2} V\left(g^{N}(.), T^{N}(.) ; b_{j}\right)}{\partial b_{R}^{2}}=-d(1+\alpha)<0 .
\end{aligned}
$$

We have to consider the nine possible cases. We present the resolution of the game where both countries choose $s d$. The other developments are similar. ${ }^{27}$

For $(s d, s d)$, we have : $a_{R^{\prime}}=a_{R}$ and $b_{R^{\prime}}=b_{R}$. The system (13) becomes:

$$
\left\{\begin{array}{c}
g\left(a_{R}, b_{R}\right)=a_{R}+d b_{R} \\
T\left(a_{R}, a_{R}, b_{R}\right)=\frac{(1+\alpha)}{2} d b_{R}^{2}
\end{array}\right.
$$

\footnotetext{
${ }^{27}$ To avoid computational errors, we have checked our calculations with Mathematica. The details are available upon request.
} 
Substituting these expressions in (14) and (15), one can determine the optimal policies choosen by the representatives in the case of strong delegation. These choices are solution of the following system:

$$
\left\{\begin{array}{l}
a_{R}^{N}\left(s d, s d ; a_{i}\right) \equiv \underset{a_{R} \in[\underline{a}, \bar{a}]}{\arg \max }\left\{U\left(g^{N}\left(a_{R}, b_{R}\right), T^{N}\left(a_{R}, a_{R}, b_{R}\right) ; a_{i}\right)\right\} \\
b_{R}^{N}\left(s d, s d ; b_{j}\right) \equiv \underset{b_{R} \in[\underline{b}, \bar{b}]}{\arg \max }\left\{V\left(g^{N}\left(a_{R}, b_{R}\right), T^{N}\left(a_{R}, a_{R}, b_{R}\right) ; b_{j}\right)\right\}
\end{array}\right.
$$

which yields to:

$$
\left\{\begin{array}{c}
a_{R}^{N}\left(s d, s d ; a_{i}\right)=a_{i}-\frac{1}{1+\alpha} d b_{R} \\
b_{R}^{N}\left(s d, s d ; b_{j}\right)=\frac{b_{j}}{1+\alpha}
\end{array}\right.
$$

Applying the MVT to (17) involves:

$$
\left\{\begin{array}{c}
a_{R}^{N}\left(s d, s d ; A_{m}\right)=A_{m}-\frac{1}{1+\alpha} d B_{m} \\
b_{R}^{N}\left(s d, s d ; B_{m}\right)=\frac{B_{m}}{1+\alpha}
\end{array}\right.
$$

We deduce that

$$
\left\{\begin{array}{c}
g^{N}(s d, s d)=A_{m} \\
T^{N}(s d, s d)=\frac{1}{2(1+\alpha)} d B_{m}^{2}
\end{array}\right.
$$

and

$$
\begin{aligned}
U^{N}(s d, s d) & =\frac{1}{2} A_{m}^{2}+\frac{1}{2(1+\alpha)} d^{2} B_{m}^{2} \\
V^{N}(s d, s d) & =A_{m} B_{m}-\frac{1}{2(1+\alpha)} d B_{m}^{2} \\
W^{N}(s d, s d) & =A_{m}\left(A-\frac{A_{m}}{2}+d B\right) .
\end{aligned}
$$

By declining this resolution method through the eight other cases, we deduce TABLE 1. For country 1, the strategy $w d$ and ref are strictly dominated by the strategy $s d$. Indeed, we have:

$$
\begin{aligned}
U^{N}(s d, s d)-U^{N}(w d, s d) & =\frac{2-\alpha+\alpha^{2}}{8(1+\alpha)} d^{2} B_{m}^{2}>0 \\
U^{N}(s d, s d)-U^{N}(\text { ref }, s d) & =U^{N}(\text { sd, ref })-U^{N}(\text { ref }, \text { ref })=\frac{1}{2(1+\alpha)^{2}} d^{2} B_{m}^{2}>0 \\
U^{N}(\text { sd, ref })-U^{N}(w d, r e f) & =\frac{1+\alpha-\alpha^{2}}{2(2-\alpha)} d^{2} B_{m}^{2}>0 .
\end{aligned}
$$

If country 1 plays $s d$, country 2 will play $s d$ since $V^{N}(s d, s d)>V^{N}(s d, r e f) .{ }^{28}$ We can conclude that $(s d, s d)$ is the unique Perfect Nash Equilibrium of the game. Note that: $\forall(x, y) \in\{s d, w d, r e f\}^{2}$, $W^{N}(x, y)=W_{1}(x, y)$ for $\alpha=1$ and $W^{N}(x, y)=W_{2}(x, y)$ for $\alpha=0$. Using the preceding results yields to:

$$
\begin{aligned}
W^{N}(\text { ref }, \text { ref })-W^{N}(\text { sd }, \text { sd }) & =W^{N}(\text { ref, ref })-W^{N}(\text { sd, ref }) \\
& =\frac{1}{2} d B_{m}\left[2\left(A-A_{m}\right)+d\left(2 B-B_{m}\right)\right] \\
W^{N}(\text { ref }, \text { ref })-W^{N}(\text { ref }, s d) & =\frac{\alpha}{2(1+\alpha)^{2}} d B_{m}\left[2(1+\alpha)\left(A-A_{m}\right)+d\left(2(1+\alpha) B-(2+\alpha) B_{m}\right)\right] \\
W^{N}(\text { ref, ref })-W^{N}(w d, s d) & =\frac{1}{8} d B_{m}\left[4\left(A-A_{m}\right)+d\left(4 B-3 B_{m}\right)\right] \\
W^{N}(\text { ref, ref })-W^{N}(w d, r e f) & =\frac{1-\alpha}{2(2-\alpha)^{2}} d B_{m}\left[2(2-\alpha)\left(A-A_{m}\right)+d\left(2(2-\alpha) B-(3-\alpha) B_{m}\right)\right] .
\end{aligned}
$$

28 Note that: $\frac{1}{2(1+\alpha)}<\frac{1}{2}<\frac{1+\alpha}{2}, \forall \alpha \in[0,1]$. 
We deduce that $\forall \alpha \in[0,1]$, if $A_{m} \leqslant A$ and $B_{m} \leqslant \frac{4}{3} B$, we have:

$$
W^{N}(r e f, r e f)=\max \left\{W^{N}(s d, s d), W^{N}(r e f, s d), W^{N}(w d, s d), W^{N}(w d, r e f)\right\} .
$$

\section{A.2 Ex post Referendum}

We denote by $U_{R a t}^{N}(x, y), V_{R a t}^{N}(x, y)$ and $W_{R a t}^{N}(x, y)$ the equilibrium values of the utilities and the aggregate welfare for the couple strategies $(x, y)$. As in APPENDIX A.1, we restrict our presentation to the resolution of the game where both countries choose $s d$. The other developments are available upon request. For $(s d, s d)$, we have: $a_{R^{\prime}}=a_{R}$ and $b_{R^{\prime}}=b_{R}$. We consider four cases, depending on the values of the Lagrange multipliers, $\lambda$ and $\mu$.

1. - If $\lambda=0$ and $\mu=0$, we obtain the same solution as in the non-constrained case, which yields to rejecting this case since: $V^{N}(s d, s d)=A_{m} B_{m}-\frac{1}{2(1+\alpha)} d B_{m}^{2}<V^{\text {dec }}\left(A_{m}, B_{m}\right)$ (see Table 3).

- If $\lambda \neq 0$ and $\mu \neq 0$, we are back to the decentralized equilibrium: $U_{R a t}^{N}(s d, s d)=U^{\operatorname{dec}}\left(A_{m}, B_{m}\right)$ and $V_{R a t}^{N}(s d, s d)=V^{\text {dec }}\left(A_{m}, B_{m}\right)$.

- If $\lambda \neq 0$ and $\mu=0$, the first constraint is binding: $U\left(g, T ; A_{m}\right)=U^{d e c}\left(a_{R^{\prime}} ; A_{m}\right)$. The maximization of (16) yields to:

$$
\left\{\begin{array}{c}
g=a_{R}+d b_{R}+\frac{d \lambda\left(A_{m}-a_{R}\right)}{1-\alpha} \\
T=\frac{d\left[\lambda\left(a_{R}-A_{m}\right)-(1-\alpha) b_{R}\right]\left[\left(A_{m}-a_{R}\right) \lambda(1+\alpha+d \lambda)-(1-\alpha) b_{R}(1+\alpha-d \lambda)\right]}{2(1-\alpha)^{2}(1-d \lambda)}
\end{array}\right.
$$

Substituting these expressions of $T$ and $g$, we determine the identity of the representatives:

$$
\left\{\begin{array}{c}
a_{R}=\frac{A_{m}\left[(1-\lambda d) \alpha^{3}-(1-2 \lambda d) \alpha^{2}+(1-\lambda d)^{2} \alpha+(1-\lambda d)^{3}\right]-d B_{m}(1-\alpha)^{2}(1-d \lambda)^{2}}{\alpha^{3}(1-\lambda d)-\alpha^{2}(1-2 \lambda)+\alpha(1-\lambda d)^{2}+(1-\lambda d)^{3}} \\
b_{R}=\frac{B_{m}(1-\lambda d)(1-\alpha-\lambda d)[1-\alpha-\lambda d(2-\alpha)]}{\alpha^{3}(1-\lambda d)-\alpha^{2}(1-2 \lambda d)+\alpha(1-\lambda d)^{2}+(1-\lambda d)^{3}}
\end{array}\right.
$$

Using the expressions of $g, T, a_{R}$ and $b_{R}$, we determine for which value of $\lambda(>0)$, the other constraint, formally $U\left(g, T ; A_{m}\right)=U^{\operatorname{dec}}\left(a_{R^{\prime}} ; A_{m}\right)$, is respected. Except for $\lambda=\frac{1}{d}$, which yields to an indeterminate form of $T$ and thus of $U($.$) and V($.$) , there are only two possible$ solutions for $\lambda$ : $\lambda_{1}=\frac{1-\alpha}{d}$ and $\lambda_{2}=\frac{1-\alpha}{d(2-\alpha)}$. Considering $\lambda_{1}$, both constraints are binding, since $g=A_{m}$ and $T=0$. The utility values are then equivalent to those at the decentralized equilibrium. For $\lambda_{2}=\frac{1-\alpha}{d(2-\alpha)}$, we observe that $g_{R a t}^{N}(s d, s d)=A_{m}-(1-\alpha) d B_{m}<g^{d e c}$ and $T>0$, it is then obvious that the median voter of country 2 would be better under separation and reject political integration.

- If $\lambda=0$ and $\mu \neq 0$, the second constraint is binding: $V\left(g, T ; B_{m}\right)=V^{\text {dec }}\left(a_{R^{\prime}} ; B_{m}\right)$, which involves: $T=B_{m}\left(g-A_{m}\right)$ or equivalently $g=A_{m}+\frac{T}{B_{m}}$. The maximization of (16) involves:

$$
\left\{\begin{array}{c}
g=\frac{(1-\alpha)\left(a_{R}+d b_{R}\right)+\mu\left(a_{R}+d B_{m}\right)}{1-\alpha+\mu} \\
T=\frac{d\left[b_{R}(1-\alpha)+\mu B_{m}\right]\left[(1+\alpha) b_{R}+\mu B_{m}\right]}{2(1+\mu)(1-\alpha+\mu)}
\end{array}\right.
$$

After substitution, we deduce the identity of the country's representative:

$$
\left\{\begin{array}{c}
a_{R}=A_{m}-\frac{d B_{m}}{1+\alpha} \\
b_{R}=\frac{[1-\alpha(1+\mu)] B_{m}}{1-\alpha^{2}}
\end{array}\right.
$$

Using these expressions, we determine the value of $\mu$ which insures that $V\left(g, T ; B_{m}\right)=$ $V^{\text {dec }}\left(a_{R^{\prime}} ; B_{m}\right)$. It yields: $\mu=\frac{1-\alpha}{2 \alpha-1}$. Note that $\mu>0$ involves that $\alpha>\frac{1}{2}$. Under this assumption, the equilibrium levels of the utility function correspond to the decentralized one.

To resume the case $(s d, s d)$, we obtain systematically the decentralized equilibrium's values, with: $U_{R a t}^{N}(s d, s d)=\frac{A_{m}^{2}}{2}$ and $V_{R a t}^{N}(s d, s d)=A_{m} B_{m}$. 
The equilibrium payments of the nine situations are presented in Table 4 . Note that for country 1 , the strategies $s d$ and ref are strictly dominated by the strategy $w d$. Indeed, we have:

$$
\begin{aligned}
U_{\text {Rat }}^{N}(w d, s d)-U_{\text {Rat }}^{N}(s d, s d) & =U_{\text {Rat }}^{N}(w d, s d)-U_{\text {Rat }}^{N}(\text { ref }, s d)=\frac{2-\alpha}{8} d^{2} B_{m}^{2}>0, \\
U_{\text {Rat }}^{N}(w d, r e f)-U_{\text {Rat }}^{N}(s d, r e f) & =\frac{1}{2(1+\alpha)^{2}} d^{2} B_{m}^{2}>0, \\
U_{\text {Rat }}^{N}(w d, \text { ref })-U_{\text {Rat }}^{N}(\text { ref }, \text { ref }) & =\frac{(1-\alpha)^{2}}{2(2-\alpha)} d^{2} B_{m}^{2}>0 .
\end{aligned}
$$

If country 1 plays $w d$, country 2 will play $s d$ since $V_{R a t}^{N}(w d, s d)-V_{R a t}^{N}(w d, r e f)=\frac{\alpha\left(4-3 \alpha+\alpha^{2}\right)}{8(2-\alpha)^{2}} d B_{m}^{2}>0$.

\begin{tabular}{|c|c|c|c|}
\hline & \multicolumn{3}{|c|}{ Country 2} \\
\hline & & $s d$ & ref \\
\hline \multirow{3}{*}{ Country 1} & $s d$ & $\begin{array}{c}U^{N}(s d, s d)=\frac{1}{2} A_{m}^{2}+\frac{1}{2(1+\alpha)} d^{2} B_{m}^{2} \\
V^{N}(s d, s d)=A_{m} B_{m}-\frac{1}{2(1+\alpha)} d B_{m}^{2} .\end{array}$ & $\begin{array}{c}U^{N}(\text { sd, ref })=\frac{1}{2} A_{m}^{2}+\frac{1+\alpha}{2} d^{2} B_{m}^{2}, \\
V^{N}(\text { sd, ref })=A_{m} B_{m}-\frac{1+\alpha}{2} d B_{m}^{2} .\end{array}$ \\
\hline & $w d$ & $\begin{aligned} U^{N}(w d, s d) & =\frac{1}{2} A_{m}^{2}+\frac{2-\alpha}{8} d^{2} B_{m}^{2} \\
V^{N}(w d, s d) & =A_{m} B_{m}+\frac{1+\alpha}{8} d B_{m}^{2}\end{aligned}$ & $\begin{array}{c}U^{N}(w d, \text { ref })=\frac{1}{2} A_{m}^{2}+\frac{1}{2(2-\alpha)} d^{2} B_{m}^{2} \\
V^{N}(w d, \text { ref })=A_{m} B_{m}+\frac{1-\alpha}{2(2-\alpha)^{2}} d B_{m}^{2}\end{array}$ \\
\hline & ref & $\begin{array}{l}U^{N}(\text { ref }, s d)=\frac{1}{2} A_{m}^{2}+\frac{\alpha}{2(1+\alpha)^{2}} d^{2} B_{m}^{2}, \\
V^{N}(\text { ref }, s d)=A_{m} B_{m}-\frac{1}{2(1+\alpha)} d B_{m}^{2} .\end{array}$ & $\begin{array}{c}U^{N}(\text { ref }, \text { ref })=\frac{1}{2} A_{m}^{2}+\frac{\alpha}{2} d^{2} B_{m}^{2}, \\
V^{N}(\text { ref, ref })=A_{m} B_{m}+\frac{1-\alpha}{2} d B_{m}^{2} .\end{array}$ \\
\hline
\end{tabular}
We can conclude that $(w d, s d)$ is the unique Nash equilibrium of the game.

\section{A.3 Tables}

Table 1: Normal form of the Negotiation game.

\begin{tabular}{|l|l|l|l|}
\cline { 2 - 4 } \multicolumn{1}{l|}{ Country 2} \\
\hline & & Leads & Follows \\
\hline & & $U^{N}(s d, s d)=\frac{1}{2} A_{m}^{2}+\frac{1}{2(1+\alpha)} d^{2} B_{m}^{2}$, & $U^{1}(s d, s d)=\frac{1}{2} A_{m}^{2}+\frac{1}{4} d^{2} B_{m}^{2}$, \\
& Leads & $V^{N}(s d, s d)=A_{m} B_{m}-\frac{1}{2(1+\alpha)} d B_{m}^{2}$. & $V^{1}(s d, s d)=A_{m} B_{m}-\frac{1}{4} d B_{m}^{2}$. \\
\cline { 2 - 4 } & Follows & $U^{2}(s d, s d)=\frac{1}{2} A_{m}^{2}+\frac{1}{2} d^{2} B_{m}^{2}$, & $U^{\text {dec }}=\frac{1}{2} A_{m}^{2}$, \\
& $V^{2}(s d, s d)=A_{m} B_{m}-\frac{1}{2} d B_{m}^{2}$. & $V^{\text {dec }}=A_{m} B_{m}$. \\
\hline
\end{tabular}

Table 2: Normal form of the Preplay game. 


\begin{tabular}{|c|c|c|c|}
\hline & \multicolumn{3}{|c|}{ Country 2} \\
\hline & & $s d$ & ref \\
\hline \multirow{3}{*}{ Country 1} & $s d$ & $\begin{array}{c}U_{R a t}^{N}(s d, s d)=\frac{1}{2} A_{m}^{2} \\
V_{R a t}^{N}(s d, s d)=A_{m} B_{m} .\end{array}$ & $\begin{array}{c}U_{R a t}^{N}(s d, r e f)=\frac{1}{2} A_{m}^{2}, \\
V_{R a t}^{N}(s d, r e f)=A_{m} B_{m} .\end{array}$ \\
\hline & $w d$ & $\begin{aligned} U_{\text {Rat }}^{N}(w d, s d) & =\frac{1}{2} A_{m}^{2}+\frac{2-\alpha}{8} d^{2} B_{m}^{2}, \\
V_{R a t}^{N}(w d, s d) & =A_{m} B_{m}+\frac{1+\alpha}{8} d B_{m}^{2} .\end{aligned}$ & $\begin{array}{c}U_{R a t}^{N}(w d, r e f)=\frac{1}{2} A_{m}^{2}+\frac{1}{2(2-\alpha)} d^{2} B_{m}^{2} \\
V_{R a t}^{N}(w d, r e f)=A_{m} B_{m}+\frac{1-\alpha}{2(2-\alpha)^{2}} d B_{m}^{2}\end{array}$ \\
\hline & ref & $\begin{array}{c}U_{R a t}^{N}(\text { ref }, s d)=\frac{1}{2} A_{m}^{2} \\
V_{\text {Rat }}^{N}(\text { ref }, s d)=A_{m} B_{m} .\end{array}$ & $\begin{array}{c}U_{\text {Rat }}^{N}(\text { ref }, \text { ref })=\frac{1}{2} A_{m}^{2}+\frac{\alpha}{2} d^{2} B_{m}^{2}, \\
V_{\text {Rat }}^{N}(\text { ref }, \text { ref })=A_{m} B_{m}+\frac{1-\alpha}{2} d B_{m}^{2} .\end{array}$ \\
\hline
\end{tabular}

Table 3: Normal form of the Negotiation game with an ex post referendum. 